OPEN ACCESS

Edited by:

Ye Zeng,

Sichuan University, China

Reviewed by:

Rocío Salceda

National Autonomous University

of Mexico, Mexico

Hongyan Kang,

Beihang University, China

*Correspondence:

David O. Bates

David.Bates@nottingham.ac.uk

Jacqueline L. Whatmore

J.L.Whatmore@exeter.ac.uk

Specialty section:

This article was submitted to

Signaling,

a section of the journal

Frontiers in Cell and Developmental

Biology

Received: 14 June 2021

Accepted: 29 July 2021

Published: 07 September 2021

Citation:

Allen CL, Wolanska K, Malhi NK, Benest AV, Wood ME, Amoaku W,

Torregrossa R, Whiteman M,

Bates DO and Whatmore JL (2021)

Hydrogen Sulfide Is a Novel Protector

of the Retinal Glycocalyx

and Endothelial Permeability Barrier.

Front. Cell Dev. Biol. 9:724905.

doi: 10.3389/fcell.2021.724905

\section{Hydrogen Sulfide Is a Novel Protector of the Retinal Glycocalyx and Endothelial Permeability Barrier}

\author{
Claire L. Allen ${ }^{1}$, Katarzyna Wolanska ${ }^{2}$, Naseeb K. Malhi', Andrew V. Benest ${ }^{1}$, \\ Mark E. Wood ${ }^{3}$, Winfried Amoaku', Roberta Torregrossa' ${ }^{2}$, Matthew Whiteman'2, \\ David O. Bates ${ }^{1 *}$ and Jacqueline L. Whatmore ${ }^{2 *}$
}

\begin{abstract}
${ }^{1}$ Cancer Biology, Division of Cancer and Stem Cells, School of Medicine, Biodiscovery Institute, University of Nottingham, Nottingham, United Kingdom, ${ }^{2}$ The Institute of Biomedical and Clinical Science, University of Exeter Medical School, St. Luke's Campus, University of Exeter, Exeter, United Kingdom, ${ }^{3}$ Biosciences, College of Life and Environmental Science, University of Exeter, Exeter, United Kingdom, ${ }^{4}$ Academic Ophthalmology, Division of Clinical Neuroscience, School of Medicine, University of Nottingham, Nottingham, United Kingdom
\end{abstract}

Significantly reduced levels of the anti-inflammatory gaseous transmitter hydrogen sulfide $\left(\mathrm{H}_{2} \mathrm{~S}\right)$ are observed in diabetic patients and correlate with microvascular dysfunction. $\mathrm{H}_{2} \mathrm{~S}$ may protect the microvasculature by preventing loss of the endothelial glycocalyx. We tested the hypothesis that $\mathrm{H}_{2} \mathrm{~S}$ could prevent or treat retinal microvascular endothelial dysfunction in diabetes. Bovine retinal endothelial cells (BRECs) were exposed to normal ( $\mathrm{NG}, 5.5 \mathrm{mmol} / \mathrm{L})$ or high glucose $(\mathrm{HG}$, $25 \mathrm{mmol} / \mathrm{L}) \pm$ the slow-release $\mathrm{H}_{2} \mathrm{~S}$ donor NaGYY4137 in vitro. Glycocalyx coverage (stained with WGA-FITC) and calcein-labeled monocyte adherence were measured. In vivo, fundus fluorescein angiography (FFA) was performed in normal and streptozotocin-induced (STZ) diabetic rats. Animals received intraocular injection of NaGYY4137 (1 $\mu \mathrm{M})$ or the mitochondrial-targeted $\mathrm{H}_{2} \mathrm{~S}$ donor AP39 (100 nM) simultaneously with STZ (prevention) or on day 6 after STZ (treatment), and the ratio of interstitial to vascular fluorescence was used to estimate apparent permeability. NaGYY4137 prevented HG-induced loss of BREC glycocalyx, increased monocyte binding to BRECs $(p \leq 0.001)$, and increased overall glycocalyx coverage $(p \leq 0.001)$. In rats, the STZ-induced increase in apparent retinal vascular permeability $(p \leq 0.01)$ was significantly prevented by pre-treatment with NaGYY4137 and AP39 $(p<0.05)$ and stabilized by their post-STZ administration. NaGYY4137 also reduced the number of acellular capillaries (collagen IV + /IB4-) in the diabetic retina in both groups $(p \leq 0.05)$. We conclude that NaGYY4137 and AP39 protected the retinal glycocalyx and endothelial permeability barrier from diabetes-associated loss of integrity and reduced the progression of diabetic retinopathy (DR). Hydrogen sulfide donors that target the glycocalyx may therefore be a therapeutic candidate for DR.

Keywords: glycocalyx, retinal permeability, diabetes, hydrogen sulfide, inflammation, mitochondria, slow-release hydrogen sulfide donors 


\section{INTRODUCTION}

Loss of integrity of the vascular permeability barrier is associated with a range of pathological conditions. In particular, increased permeability is observed in diabetes, and in hyperglycemic conditions (Gillies et al., 1997; Brownlee, 2001; Allen and Bayraktutan, 2009; Saker et al., 2014) where it is associated with the pathogenesis of life-altering diabetic microvascular complications such as retinopathy (Sander et al., 2007). The vascular permeability barrier is formed of endothelial cells (ECs), their underlying basement membrane, and the endothelial glycocalyx. The latter is now recognized as a key regulator of permeability as demonstrated by a range of studies showing that selective loss of specific glycocalyx components is associated with altered permeability properties in various vascular beds (Jeansson and Haraldsson, 2003; Singh et al., 2007; Landsverk et al., 2012; Betteridge et al., 2017; Onions et al., 2019).

A role for endothelial glycocalyx damage in diabetesassociated vascular changes has been described. Glycocalyx reduction is associated with increased vascular permeability and increased leucocyte and platelet adhesion in acute hyperglycemia and diabetes (Nieuwdorp et al., 2006a,b; Broekhuizen et al., 2010; Kumase et al., 2010), which were reversed by glycocalyx restoration experimentally in animals (Henry and Duling, 1999; Constantinescu et al., 2003). Strategies to reverse or reduce glycocalyx damage in diabetes have the potential to rescue some of the potentially damaging vascular changes that underlie the development of vascular complications such as retinopathy.

We hypothesized that exogenous application of hydrogen sulfide $\left(\mathrm{H}_{2} \mathrm{~S}\right)$ may protect the glycocalyx in diabetes, reversing or preventing the retinal vascular leakage observed in diabetic retinopathy (DR). Hydrogen sulfide has recently been identified as a seemingly ubiquitous "gaseous mediator" in mammals and humans where it is synthesized by multiple cell types by at least four distinct enzyme systems utilizing endogenous sulfur-containing amino acids. These systems include the cytosolic cystathionase (CSE), cystathionine- $\beta$-synthase (CBS), mitochondrial cysteine aminotransferase/3-mercaptopyruvate sulfurtransferase (CAT/3MST), and D-amino acid oxidase/3mercaptopyruvate sulfurtransferase (DAO/3MST) (Whiteman et al., 2011; Szabo, 2012; Wang, 2012; Szabo et al., 2014). The first three, at least have been demonstrated in ECs (Wang, 2012; Tao et al., 2013; Mitidieri et al., 2020). Experimentally, manipulation of $\mathrm{H}_{2} \mathrm{~S}$ level has been achieved by pharmacological inhibition or genetic removal of enzyme systems for $\mathrm{H}_{2} \mathrm{~S}$ and the use of $\mathrm{H}_{2} \mathrm{~S}$ delivery molecules, albeit generally limited to the use of simple inorganic sulfide salts [e.g., sodium hydrosulfide $(\mathrm{NaSH})$ or disodium sulfide $\left.\left(\mathrm{Na}_{2} \mathrm{~S}\right)\right]$. These studies have revealed that $\mathrm{H}_{2} \mathrm{~S}$ and/or physiologically derived species exert a wide variety of effects on different organ systems including regulation of vascular tone (Yang et al., 2008; Kanagy et al., 2017; Szabo, 2017), inflammation (Whiteman and Winyard, 2011), aging and health span (Ng et al., 2018; Zivanovic et al., 2019), and more recently as a regulator of retinal physiology (Du et al., 2017).

There is increasing evidence for impaired vascular EC synthesis and/or bioavailability of $\mathrm{H}_{2} \mathrm{~S}$ in diabetes (Szabo, 2012). Lower vascular and/or tissue levels of " $\mathrm{H}_{2} \mathrm{~S}$ " have been observed in humans with diabetes (Whiteman et al., 2010a; Suzuki et al., 2017), and in several animal diabetic models, including streptozotocin (STZ)-treated rats (Yusuf et al., 2005; Si et al., 2013; Zhou et al., 2014) and mice (Suzuki et al., 2011) and in db/db (Peake et al., 2013; Sun et al., 2018), ob/ob (Zhao et al., 2017), Akita (Kundu et al., 2013; John et al., 2017), and NOD (Brancaleone et al., 2008) mice. Administration of often high doses of $\mathrm{H}_{2} \mathrm{~S}$ via sulfide salts at least partially prevented the diabetic phenotype in some of these studies. In the STZ diabetes model specifically, retinal levels of $\mathrm{H}_{2} \mathrm{~S}$ were lower in diabetic animals compared with controls ( $\mathrm{Si}$ et al., 2013), and retinal capillary leakage, VEGF levels, and oxidative stress markers were partially normalized after $\mathrm{NaSH}$ treatment (Si et al., 2013). NaSH administration also partially restored mitochondrial function, e.g., increased ATP synthesis and complex II and III activity and prevented mitochondrial oxidant production and mitochondrial swelling, demonstrating a likely mitochondrial target for pharmacological $\mathrm{H}_{2} \mathrm{~S}$ ( $\mathrm{Si}$ et al., 2013). Collectively, these studies strongly suggest that diabetes and diabetic retinopathy (DR) result from " $\mathrm{H}_{2} \mathrm{~S}$ deficiency," which could at least be partially overcome by pharmacological manipulation of mitochondrial $\mathrm{H}_{2} \mathrm{~S}$ levels.

It is important to note that these previous studies on $\mathrm{H}_{2} \mathrm{~S}$ and diabetes have exclusively relied on the use of sulfide salts to generate $\mathrm{H}_{2} \mathrm{~S}$ (e.g., $\mathrm{NaSH}$ and $\mathrm{Na}_{2} \mathrm{~S}$ ). While useful laboratory tools for $\mathrm{H}_{2} \mathrm{~S}$ generation, they are not without severe limitations (Whiteman et al., 2011). These include generation of an instant, and unphysiological bolus of $\mathrm{H}_{2} \mathrm{~S}$ by $\mathrm{pH}$-dependent dissociation (and rapid decay), whereas endogenous organic enzymatic $\mathrm{H}_{2} \mathrm{~S}$ synthesis produces low levels of $\mathrm{H}_{2} \mathrm{~S}$ over prolonged periods of time (Li et al., 2008; Whiteman et al., 2010b, 2011; Kabil and Banerjee, 2014).

It is now recognized that mitochondrial oxidative stress may contribute to the pathogenesis of diabetic endothelial dysfunction (Brownlee, 2005) and that in diabetes, the primary target for $\mathrm{H}_{2} \mathrm{~S}$ activity appears to be the mitochondria where it is used as an electron source for respiration to reduce oxidative stress (Módis et al., 2014; Szabo et al., 2014). This is supported by data indicating that mitochondrial-targeted slow-release $\mathrm{H}_{2} \mathrm{~S}$ donors preserved cellular bioenergetics and increased levels of $\mathrm{Nrf} 2$ and peroxisome proliferator-activated receptor-gamma coactivator (PGC-1 $\alpha$ ), key regulators of mitochondrial antioxidant capacity, bioenergetics, and biogenesis, both in vitro and in vivo in response to UVA-induced photoaging (Lohakul et al., 2021).

However, $\mathrm{H}_{2} \mathrm{~S}$ concentrations (derived from sulfide salts) that are required to reverse mitochondrial dysfunction in the vasculature (e.g., in diabetic rats) are unattainable (Suzuki et al., 2011; Montoya and Pluth, 2016). This is presumably because $\mathrm{H}_{2} \mathrm{~S}$ from these tools is generated immediately, locally, and not targeted to mitochondria. With the development of the slowrelease cytosolic donor sodium GYY4137 (Li et al., 2008) and the mitochondria-specific sulfide donor AP39 (Le Trionnaire et al., 2014) the limitations of $\mathrm{NaSH} / \mathrm{Na}_{2} \mathrm{~S}$ have been overcome. The effects on microvascular EC and in the kidney have been previously reported (Ahmad et al., 2016; Gerö et al., 2016), but to the best of our knowledge, no previous studies have reported on the effects of these molecules in DR. 
In this current study, we investigated the effects of a single dose (administered by intravitreal injection) of two slow-release $\mathrm{H}_{2} \mathrm{~S}$ donor molecules, the cytosolic sodium GYY4137 ( $\mathrm{Li}$ et al., 2008) and the mitochondria-specific sulfide donor AP39 (Le Trionnaire et al., 2014), on retinal vascular permeability in vivo in the Norway Brown rat streptozotocin-induced DR model. In addition, the effects of these two $\mathrm{H}_{2} \mathrm{~S}$ generators on in vitro EC glycocalyx thickness using bovine retinal endothelial cells (BRECs) were studied. Leucocyte adhesion to BRECs and the effects of the $\mathrm{H}_{2} \mathrm{~S}$ modulation were also evaluated in normal and high-glucose conditions.

\section{MATERIALS AND METHODS}

\section{$\mathrm{H}_{2} \mathrm{~S}$ Donor Synthesis}

The mitochondria-targeted $\mathrm{H}_{2} \mathrm{~S}$ donor AP39 was synthesized in our laboratories as previously described by our team (Le Trionnaire et al., 2014). Commercially available GYY4137 is a morpholine salt that contains unstated quantities of dichloromethane residual from its initial synthesis and which forms part of the lattice structure (at least 2 dichloromethane: 1 GYY4137 molecule) (Alexander et al., 2015), i.e., it is commercially available as $\mathrm{xCHCl}_{2}$ or a dichloromethane complex. Dichloromethane is metabolized in vivo to carbon monoxide (Ratney et al., 1974; Takano and Miyazaki, 1988). Furthermore, the morpholinium counter ion (1 morpholine: 1 GYY4137 molecule) is not biologically inert and has a half-life in rats of $\sim 90 \mathrm{~min}$ (Sohn et al., 1982). $\mathrm{LD}_{50}$ values for morpholine in rats and mice, e.g., $100-400 \mathrm{mg} / \mathrm{kg}$ for i.p. administration (Kielhorn and Rosner, 1996), are well within the commonly used doses of commercial GYY4137, e.g., 50-300 mg/kg (Lee et al., 2011; Li et al., 2013). In the eye, morpholine and dichloromethane have been reported to cause keratoconjunctivitis, focal/diffuse cataract formation, keratitis, iritis, conjunctival epithelial edema and detachment, and denudation of corneal epithelium (Ballantyne et al., 1976; Brandt and Okamoto, 1988; Toxicologycosmetic ingredient review, 1989). To avoid these clinical indications and associated toxicity, a cleaner dichloromethane and morpholine-free sodium salt synthesized as previously described was used in this study (Alexander et al., 2015).

\section{Cell Culture and Treatments}

Primary cultures of BRECs were isolated from bovine retinae dissected from eyes of freshly slaughtered cattle, by homogenization and a series of filtration steps as previously described (Chibber et al., 2000). Briefly, excess fat and muscle tissue was removed from the eye globes and the retina were dissected, placed in $20 \mathrm{ml}$ of minimal essential medium (MEM) and homogenized using a hand-held sterile glass homogenizer to dissociate the neural retina. The resulting homogenate was filtered through $80-\mu \mathrm{m}$ nylon mesh, the material remaining on the mesh was collected, and the trapped microvessels were resuspended in serum free MEM with collagenase-dispase $\left(2 \mathrm{mg} / \mathrm{ml}\right.$ ) and digested for $90 \mathrm{~min}$ at $37^{\circ} \mathrm{C}$ on a rotator shaker. Following further filtration through a $45-\mu \mathrm{m}$ polypropylene net filter, the trapped microvessel fragments were vigorously pipetted in MEM with $10 \%$ (v/v) pooled human serum, 10\% (v/v) tryptose phosphate broth (TPB), L-glutamine $2 \mathrm{mM}$, penicillin $(100 \mathrm{U} / \mathrm{ml})$, and streptomycin $(100 \mu \mathrm{g} / \mathrm{ml})$ and plated in fibronectin-coated tissue culture flasks. After $24 \mathrm{~h}$, the flasks were rinsed once with MEM to remove debris and unattached cells and refilled with fresh growth medium [MEM supplemented with $10 \%(\mathrm{v} / \mathrm{v})$ pooled human serum, $10 \%(\mathrm{v} / \mathrm{v})$ tryptose phosphate broth (TPB), L-glutamine $2 \mathrm{mmol} / \mathrm{L}$, and penicillin $(100 \mathrm{U} / \mathrm{ml})$ and streptomycin $(100 \mu \mathrm{g} / \mathrm{ml})]$. From passage 1 onward, the BRECs were cultured on gelatin-coated tissue culture flasks and human serum was replaced with $10 \%(\mathrm{v} / \mathrm{v})$ horse serum. Pericyte contamination was removed by differential trypsinization. Cultures were $>90 \%$ pure as assessed by morphology and staining for von Willebrand factor. Preliminary studies confirmed that treatment with $25 \mathrm{mmol} / \mathrm{L}$ D-mannitol as osmotic control had no effect on either the glycocalyx or leukocyte adhesion compared with the normal glucose (NG) treatment. U937 cells (human leukemic monocyte lymphoma cell line) were cultured in RPMI-1640 with 10\% (v/v) fetal bovine serum, $5.6 \mathrm{mmol} / \mathrm{L} \mathrm{D}$-glucose, $25 \mathrm{mmol} / \mathrm{L}$ HEPES, and antibiotics. Based on our preliminary results, a final concentration of $500 \mu \mathrm{mol} / \mathrm{L}$ of NaGYY4137 was used in the definitive experiment. NaGYY4137 (500 $\mu \mathrm{mol} / \mathrm{L})$ generates approximately $1 \mu \mathrm{mol} / \mathrm{L}$ or less of $\mathrm{H}_{2} \mathrm{~S}$ during the incubation period (Szabo, 2017).

\section{Glycocalyx Assessment}

A cell-based fluorescent assay, based on that described by Singh et al. (2007), was performed to quantify changes within the glycocalyx using fluorescein isothiocyanate-labeled wheat germ agglutinin (WGA-FITC). Bovine retinal endothelial cells were exposed to normal (NG, $5.5 \mathrm{mmol} / \mathrm{L})$ or high glucose $(\mathrm{HG}$, $25 \mathrm{mmol} / \mathrm{L}) \pm$ GYY4137 (500 $\mu \mathrm{mol} / \mathrm{L})$ in MEM with $0.5 \%$ bovine serum albumin (BSA, w/v) for $24 \mathrm{~h}$. Cells were washed $3 \times$ with phosphate buffered saline (PBS) and incubated with WGA-FITC $[2 \mu \mathrm{g} / \mathrm{ml}$ in HEPES-buffered phenol red-free MEM containing $0.5 \% \mathrm{BSA}(\mathrm{w} / \mathrm{v})]$ for $30 \mathrm{~min}$ at $37^{\circ} \mathrm{C}$. After washing with PBS $(3 \times)$, fluorescence intensities were measured $(\mathrm{Ex} / \mathrm{Em}$, $485 / 520 \mathrm{~nm}$ ) using a fluorescence microplate reader. Cells were lysed and the protein content of each well was measured using the bicinchoninic acid method. Results are presented as fluorescence unit/ $\mu$ g of protein.

\section{Leukocyte Adhesion Assay}

Bovine retinal endothelial cells (BRECs) were cultured to confluency in commercially available $\mu$-slide VI0.4 perfusion slides (Ibidi, München, Germany) coated first with 2\% (w/v) bovine gelatin $(2 \mathrm{~h})$ and then overnight with bovine fibronectin $(50 \mu \mathrm{g} / \mathrm{ml})$. Cells were treated with NG or HG as above. Calcein acetoxymethyl ester labeled $(0.5 \mu \mathrm{mol} / \mathrm{L}$ for $30 \mathrm{~min}) \mathrm{U} 937$ cells $\left(1 \times 10^{6} / \mathrm{ml}\right)$ were then flowed over confluent BREC cultures at a laminar shear stress of $1 \mathrm{dyne} / \mathrm{cm}^{2}$ generated by a peristaltic pump. This shear stress was chosen to mimic venular wall shear stresses that favor leucocyte adhesion in vivo (Jones et al., 1995; Sundd et al., 2011). After $6 \mathrm{~min}$, slides were washed with PBS for $1 \mathrm{~min}$ to remove non-adherent cells, fixed in $4 \%$ $(\mathrm{w} / \mathrm{v})$ paraformaldehyde, and examined using a Nikon Eclipse 
TS100 (Nikon UK Limited, Kingston upon Thames, Surrey, United Kingdom) fluorescence microscope to assess the number of adherent U937 cells (10 random fields of view/slide). All experiments were performed on at least three separate occasions. Statistical significance was tested using the Student $t$-test.

\section{Animal Ethics}

Experimental animals were treated in accordance with ARVO Statement for the Use of Animals in Ophthalmic and Vision Research and under a UK Home Office license at the University of Nottingham Biological Services Unit.

\section{Streptozotocin-Induced Diabetes}

A total of 12 male Norway Brown rats (250-300 g, Envigo, United States) were weighed and given a single intraperitoneal (i.p.) injection of STZ (50 mg/kg, Sigma-Aldrich, MO, United States). A total of six control rats were injected with $300 \mu \mathrm{l}$ of saline i.p. On days 0 and 4 and prior to sacrifice (day 7), blood glucose levels were tested using a sample of blood taken from the tail vein and an Accuchek blood glucose monitor. Rats with blood glucose levels of $15 \mathrm{mmol} / \mathrm{L}$ and above were deemed diabetic. Streptozotocin-injected rats that did not become hyperglycemic on day 4 were re-injected with STZ the following morning and subsequently included if deemed diabetic following evaluation for diabetes as outlined above.

\section{Intravitreal Injections}

Rats were anaesthetized with a single $10 \mathrm{mg} / \mathrm{ml}$ i.p. injection of Domitor (medetomidine hydrochloride, Pfizer, United Kingdom) and Ketaset (ketamine hydrochloride, Zoetis, NJ, United States). Pupils were dilated with topical applications of $5 \%(\mathrm{w} / \mathrm{v})$ phenylephrine hydrochloride (Bausch and Lomb) and 0.8\% $(\mathrm{w} / \mathrm{v})$ tropicamide (Bausch and Lomb), and eyes were coated with Lubrithal (Dechra) to prevent dehydration. A $1.5-\mathrm{cm}$ 34-gauge hypodermic needle (Hamilton, NV, United States) attached to a 5- $\mu$ l syringe (World Precision Instruments, FL, United States) was inserted through pars plana at $3 \mathrm{~mm}$ from the limbus into the vitreous of the left eye at a $45^{\circ}$ angle. Rats received $5 \mu \mathrm{l}$ of sterile PBS, $1 \mu \mathrm{mol} / \mathrm{L}$ NaGYY4137 [sodium 4-methoxyphenyl(morpholino)-phosphinodithioate], or $100 \mathrm{nmol} / \mathrm{L}$ AP39 [(10-oxo-10-(4-(3-thioxo-3H-1,2-dithiol5yl)phenoxy)decyl) triphenylphosphonium bromide] on day 0 (prevention arm) or day 6 (treatment arm).

\section{Fundus Fluorescein Angiography}

Angiography was performed as described (Allen et al., 2020). Sodium fluorescein $(\mathrm{NaF})$ dye was prepared by dissolving in sterile PBS to give a final concentration of $100 \mathrm{mg} / \mathrm{ml}$ and sterile filtered $(0.2 \mu \mathrm{m})$. Rats were anesthetized as previously described and fundus images of the retina were captured to check for any ocular abnormalities. Rats received a single $250 \mu$ l i.p. injection of sodium fluorescein $(100 \mathrm{mg} / \mathrm{ml})$, which was allowed to circulate for $\sim 60 \mathrm{~s}$ before imaging with a Micron IV Retinal Imaging Microscope (Phoenix Research Labs). The green filter was selected, and a 3-min video footage of the retina was recorded at 15 frames per second. This was carried out on days 0 and
7. Development of cataracts with resultant blurring of posterior segment view meant that some eyes $(n=2)$ were excluded from the consecutive fundus fluorescein angiography (FFA).

\section{Retinal Permeability Model}

Angiograms were imported into ImageJ software and fluorescence was measured in the interstitium and a major retinal vessel every 200 frames up to 2,400 frames. The ratio of interstitial to vascular fluorescence was adjusted for background level and plotted against time and the slope used to determine an estimate of permeability (Figure 1). Figure 1A shows images taken from rats given $\mathrm{NaF}$ and recording started within $1 \mathrm{~min}$ of injection. The large vessels of the retina are clearly seen, and the retina becomes brighter over time. To estimate a measure of permeability, the fluorescence intensity in an area with no large vessels was measured. The solute flux (number of fluorescence molecules entering the interstitium per unit time) was calculated from the change in fluorescence intensity in the window outside the major vessel, as a proportion of the fluorescence intensity in the blood vessel in the same frame, to account for any changes in focus, excitation intensity, or noise, plotted against the time in seconds. The permeability surface area product was calculated from the solute flux, the concentration gradient between the intravascular and extravascular compartments (difference in fluorescence intensity), and the area of the extravascular sample measurement according to Fick's law. In healthy Norway Brown rats, the permeability was the same 7 days after intraocular injection with $2 \mu \mathrm{l}$ saline $\left(7.47 \pm 1.74 \times 10^{-4} \mathrm{~s}^{-1}\right)$ as it was before injection $\left(6.57 \pm 2.13 \times 10^{-4} \mathrm{~s}^{-1}\right)$. Streptozotocin treatment resulted in a significant increase in blood glucose $(29.73 \pm 0.66 \mathrm{mmol} / \mathrm{L})$ after 1 week (compared with $7.92 \pm 0.37 \mathrm{mmol} / \mathrm{L}$ ), which was accompanied by a significant increase in solute flux in the retina (Figure 4), which translated to an increase in estimated permeability from $8.19 \pm 0.95 \times 10^{-4} \mathrm{~s}^{-1}$ before STZ to $13.32 \pm 1.65 \times 10^{-4} \mathrm{~s}^{-1}$ after STZ induction (Allen et al., 2020).

\section{Immunofluorescence}

After animal termination and ocular dissection (day 14), retinae were flat-mounted and blocked in 5\% (v/v) goat serum, 3\% (v/v) Triton X-100, 1\% (w/v) BSA, and stained with isolectinB4 (IB4) (Sigma Aldrich, biotin conjugated) $5 \mu \mathrm{g} / \mathrm{ml}$ and rabbit anti-collagen IV (Abcam) $5 \mu \mathrm{g} / \mathrm{ml}$ overnight at $4^{\circ} \mathrm{C}$. Streptavidin conjugated Alexafluor $4882 \mu \mathrm{g} / \mathrm{ml}$ and donkey anti-rabbit Alexafluor $5554 \mu \mathrm{g} / \mathrm{ml}$ were used to detect IB4 and collagen IV staining, respectively. Coverslips were mounted with Fluoroshield with DAPI. Images were obtained using a Leica TCS SPE confocal microscope, and all settings were maintained between images.

\section{Statistics}

All statistics and graphs were produced in GraphPad Prism 6 and statistical tests are shown in figure legends. Significant differences are indicated on graphs as asterisks, where: ${ }^{*} p \leq 0.05 ;{ }^{* *} p \leq 0.01$; $* * * p \leq 0.001$. 


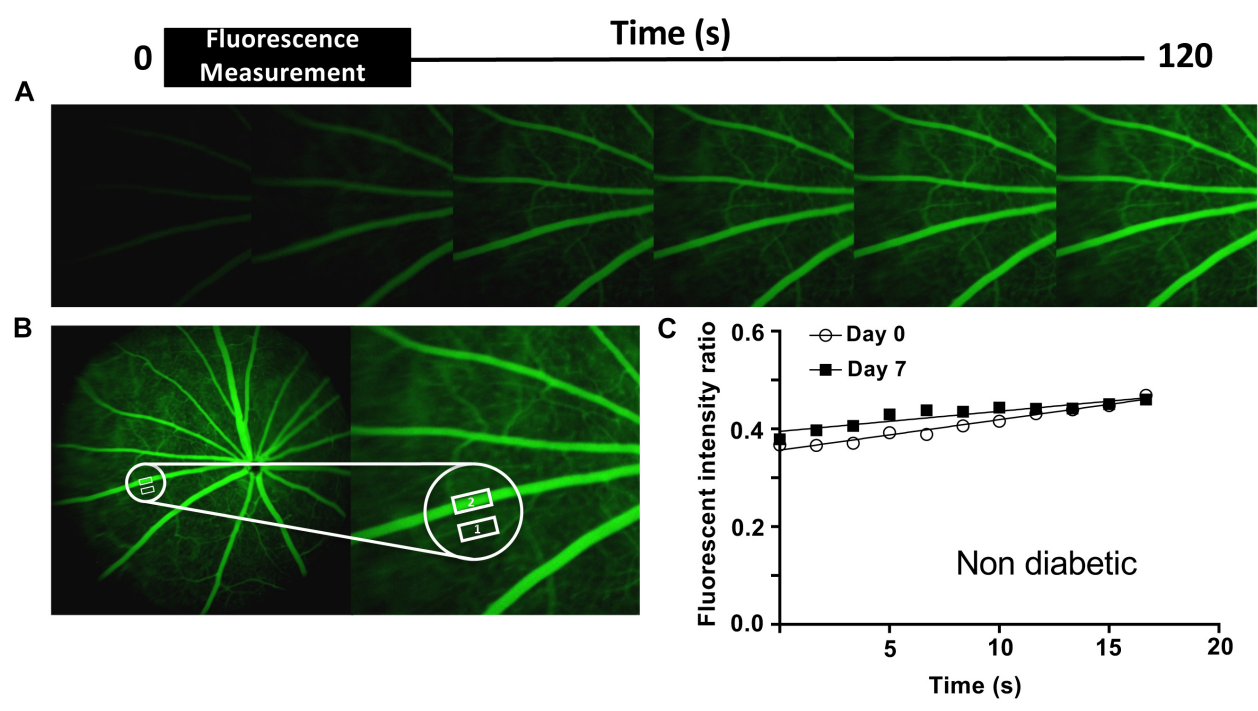

FIGURE 1 | Retinal permeability analysis model. (A) Fundus fluorescein angiography was performed in non- and diabetic Norway Brown rats treated $\pm \mathrm{H}_{2} \mathrm{~S}$ donors, on days 0 and 7 . The angiograms shown are representative of a non-diabetic animal. (B) The mean intensity of NaF in the retinal tissue (Adamis and Berman, 2008) and a main retinal vessel (Ahmad et al., 2016) were measured every 200 frames for 3 min. (C) Apparent permeability (Permeability.Surface Area product, PA) was calculated from the rate of change of extravascular fluorescence $\left(=\Delta \mathrm{l}_{\mathrm{f}} / \Delta \mathrm{t}\right)$ per unit concentration difference $(\Delta \mathrm{C})$ between blood and tissue. $\mathrm{P}=\Delta \mathrm{l}_{\mathrm{f}} / \Delta \mathrm{t} /(\Delta \mathrm{C} \times \mathrm{A})$. $\Delta \mathrm{l}_{\mathrm{f}} / \Delta \mathrm{t} \sim$ slope. $\Delta \mathrm{C}=$ difference between intra- and extravascular intensity.

\section{RESULTS}

\section{Glycocalyx Integrity}

Two hydrogen sulfide generating molecules were investigated, NaGYY4137 and AP39. The former is a slow-releasing hydrogen sulfide donor (Alexander et al., 2015) that does not target any specific part of the cell, whereas AP39 is a mitochondrial targeted donor (Le Trionnaire et al., 2014).

HG significantly reduced BREC glycocalyx in vitro (assessed by FITC-WGA staining) to $89.67 \% \pm 6.6 \%$ compared with NG control conditions (100\%), $p \leq 0.001, n=12-30$ (Figure 2). Simultaneous treatment with the slow-release $\mathrm{H}_{2} \mathrm{~S}$ donor NaGYY4137 completely reversed this loss and actually restored the glycocalyx to higher levels than observed in the NG control ( $107.49 \pm 8.13 \%$ vs. $100 \%, p \leq 0.001, n=12-30)$. Interestingly, cells incubated in NG conditions in the presence of NaGYY4137 also had significantly higher glycocalyx staining than control NG-treated cells $(106.7 \pm 6.35$ vs. $100 \%, p \leq 0.001, n=12-30)$.

Since the integrity of the glycocalyx may alter endothelial cell adhesion molecule exposure and thus influence leukocyte/endothelial binding, adhesion of U937 leukocytes to a BREC monolayer was examined under the same experimental conditions. HG significantly increased leukocyte adhesion to $348 \pm 110 \%$ vs. NG control (100\%), $p \leq 0.01, n=4$ (Figure 3). This increase was fully attenuated to control levels by incubation with NaGYY4137 (HG + NaGYY4137; $124 \pm 47 \%$ vs. HG; $348 \pm 110 \%, p \leq 0.01, n=4)$. NaGYY4137 had no significant effect on leukocyte binding in NG conditions.

\section{Retinal Permeability}

To determine the effect of hydrogen sulfide donors on retinal permeability, fluorescein fundus angiography was carried out before and after induction of diabetes with STZ. NaF was injected intraperitoneally into Norway Brown rats and the fluorescence intensity inside a large vessel and in the tissue outside a large vessel was determined over time by video-microscopy.

Retinal vascular permeability was significantly increased in the diabetic Norway Brown rats $\left(23.51 \pm 4.59 \times 10^{-4} \mathrm{~s}^{-1}, n=3\right)$ compared with normal control rats $\left(9.38 \pm 1.40 \times 10^{-4} \mathrm{~s}^{-1}\right.$, $n=6$, Figure 4) on day $28(p \leq 0.001)$ on day 28 and all other time points. In the $\mathrm{H}_{2} \mathrm{~S}$ donor treatment study no changes

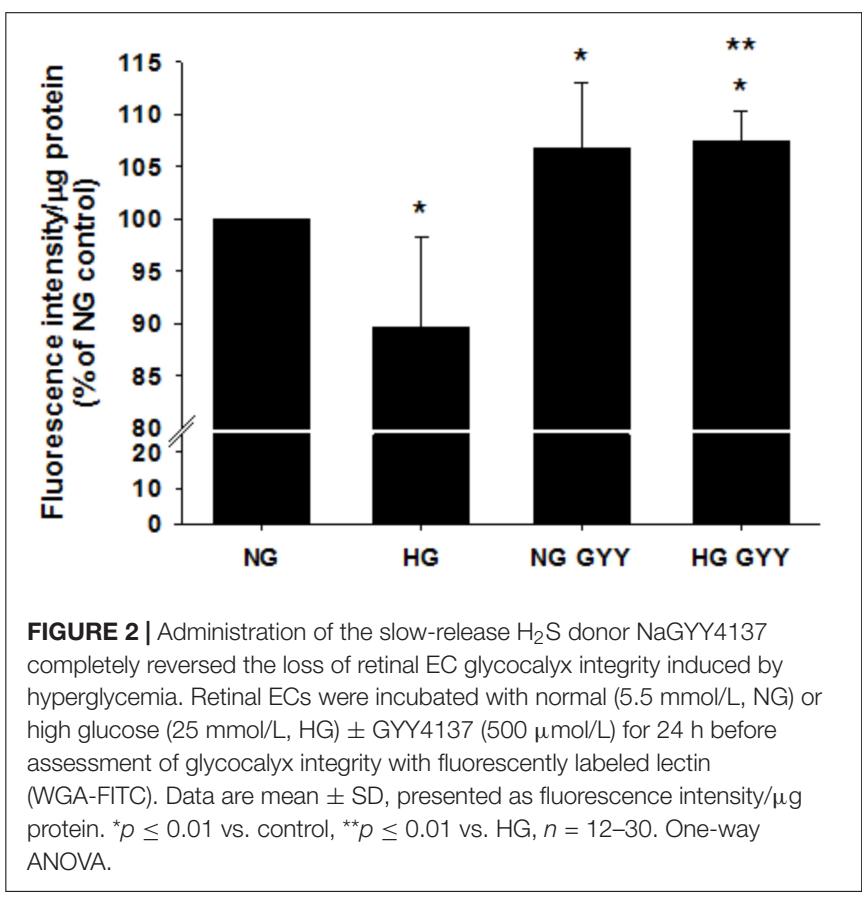


A

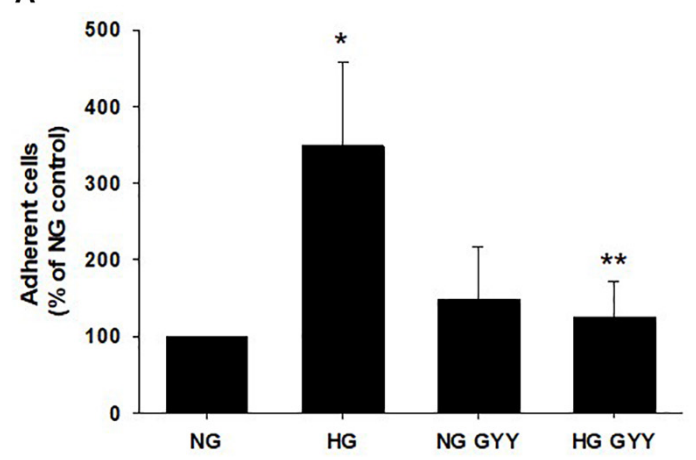

B

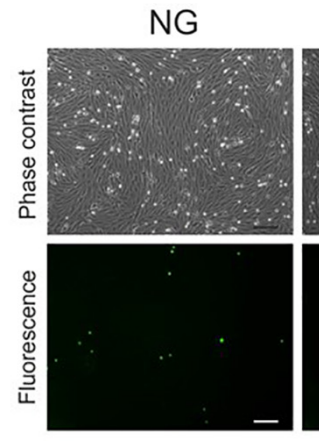

HG

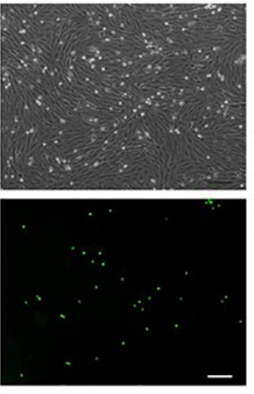

HG GYY4137

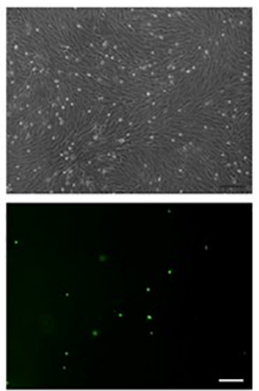

FIGURE 3 | Administration of the slow-release $\mathrm{H}_{2} \mathrm{~S}$ donor NaGYY4137 completely attenuated the increased leukocyte adhesion to retinal ECs induced by hyperglycemia. Retinal ECs were incubated with normal (5.5 mmol/L, NG) or high glucose (25 mmol/L, HG) \pm NaGYY4137 (500 $\mu$ mol/L) for 24 h before examination

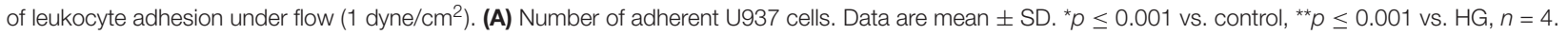
One-way ANOVA. (B) Representative bright field, phase contrast (upper panel) and corresponding fluorescence images (lower panel) of adherent U937 cells stained with calcein acetoxymethyl ester adhering to a BREC monolayer. Scale bar, $75 \mu \mathrm{m}$; original magnification, $\times 100$.

in retinal permeability were measured on day 7 compared to baseline in non-diabetic animals treated with vehicle control (saline) (Figure 5A). However, a significant $(p \leq 0.05)$ increase in retinal permeability was measured in non-insulin treated diabetic animals on day $7\left(12.16 \pm 0.98 \times 10^{-4} \mathrm{~s}^{-1}\right)$ compared to baseline $\left(9.23 \pm 1.54 \times 10^{-4} \mathrm{~s}^{-1}\right)$ (Figures 5B,C). The slowrelease hydrogen sulfide donor NaGYY4137 significantly reduced retinal vascular permeability in control, non-diabetic rats after 7 days (3.24 $\left.\pm 0.66 \times 10^{-4} \mathrm{~s}^{-1}, p \leq 0.05, n=6\right)$ vs. day $0\left(10.12 \pm 1.85 \times 10^{-4} \mathrm{~s}^{-1}\right)$ when administered as a single preventative intraocular dose pre-diabetes (Figure 5D). Similarly, NaGYY4137 given in diabetic rats significantly reduced retinal permeability on day $7\left(6.62 \pm 1.16 \times 10^{-4} \mathrm{~s}^{-1}, p \leq 0.05, n=6\right)$ vs. day $0\left(13.08 \pm 2.61 \times 10^{-4} \mathrm{~s}^{-1}\right)$ when given as a preventative treatment (Figure 5D). When NaGYY4137 was administered therapeutically, retinal permeability was reduced in control, nondiabetic animals on day $7\left(5.31 \pm 1.24 \times 10^{-4} \mathrm{~s}^{-1}, n=6\right)$ vs. day $0\left(8.90 \pm 1.19 \times 10^{-4} \mathrm{~s}^{-1}, n=6\right)$. More importantly, in animals with pre-existing diabetes, retinal permeability stabilized on day $7\left(10.27 \pm 1.21 \times 10^{-4} \mathrm{~s}^{-1}, n=6\right)$ compared to day $0\left(8.65 \pm 1.23 \times 10^{-4} \mathrm{~s}^{-1}, n=6\right)$ (Figure 5E). Administering NaGYY4137 treatment prior to the onset of diabetes gave a $68 \%$ benefit in reducing retinal permeability compared with administration to animals with pre-existing diabetes (Figure 5F).

Similarly, the mitochondrial-targeted hydrogen sulfide donor AP39 significantly reduced retinal permeability in control, nondiabetic $\left(6.14 \pm 0.90 \times 10^{-4} \mathrm{~s}^{-1}, p \leq 0.05, n=6\right)$ and diabetic rats $\left(9.84 \pm 1.48 \times 10^{-4} \mathrm{~s}^{-1}, p \leq 0.05, n=6\right)$ compared with day $0\left(10.01 \pm 1.34 \times 10^{-4} \mathrm{~s}^{-1}\right.$ and $15.52 \pm 2.75 \times 10^{-4} \mathrm{~s}^{-1}$, respectively) when administered as a single preventative dose (Figure 5G). In addition, AP39 reduced retinal permeability after a week $\left(5.93 \pm 2.25 \times 10^{-4} \mathrm{~s}^{-1}, n=6\right)$ compared with baseline $\left(9.49 \pm 1.28 \times 10^{-4} \mathrm{~s}^{-1}, p \leq 0.05, n=6\right)$ in control animals when administered therapeutically. However, in diabetic animals, AP39, when administered therapeutically, stabilized retinal permeability $\left(13.63 \pm 2.56 \times 10^{-4} \mathrm{~s}^{-1}, n=5\right)$ on day 7 versus baseline $\left(8.99 \pm 1.31 \times 10^{-4} \mathrm{~s}^{-1}, n=5\right)$ (Figure $5 \mathbf{H}$ ). Similar to NaGYY4137, administering AP39 treatment prior to the onset of diabetes gave an $18 \%$ benefit in reducing retinal permeability when compared with animals with pre-existing diabetes (Figure 5I). Overall, both $\mathrm{H}_{2} \mathrm{~S}$ donors were more effective in reducing retinal permeability when given to animals prior to the onset of diabetes. In addition, NaGYY4137 showed greater efficacy than a 10 -fold lower dose of the mitochondrial targeted AP39 compound.

\section{Acellular Capillary Formation}

One of the contributing factors to the pathogenesis of DR is the presence of acellular capillaries within the retina. These vessels maintain a basement membrane but have lost the supporting pericytes and EC cells and thus have no blood flow, promoting retinal ischemia. In order to assess the effects of NaGYY4137 on acellular capillary formation, retinae were collected at the end of the retinal permeability study and stained for isolectin B4, an EC marker, and collagen IV, a major constituent of the basement membrane. NaGYY4137 was found to reduce the number of acellular capillaries (collagen IV $+/$ IB4-) in the diabetic retinae in both the prevention and treatment group to $80.2 \pm 13.9 \mathrm{~mm}^{-2}$ and $66.1 \pm 7.1 \mathrm{~mm}^{-2}$, respectively, compared with $113.6 \pm 11.7 \mathrm{~mm}^{-2}$ in the diabetic retinae $(p \leq 0.05, n=3$, Figure 6). Despite the increased effectiveness of NaGYY4137 in reducing retinal permeability when administered prior to diabetes onset, the time of administration appeared to have no difference in acellular capillary formation.

\section{DISCUSSION}

The data presented here indicate, for the first time, that (a) high glucose-driven glycocalyx loss, (b) high glucose-enhanced leukocyte adhesion to the endothelium, and (c) diabetesassociated increases in retinal permeability can all be reversed by administration of a slow-release $\mathrm{H}_{2} \mathrm{~S}$ donor.

Hyperglycemia-related low-grade persistent inflammation is thought to contribute to the pathology of early DR (Adamis and Berman, 2008). Patients with DR have elevated ocular 
A

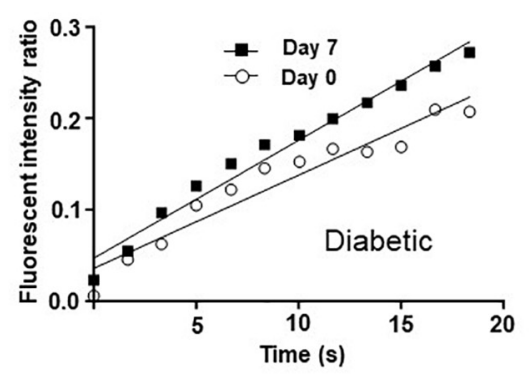

B

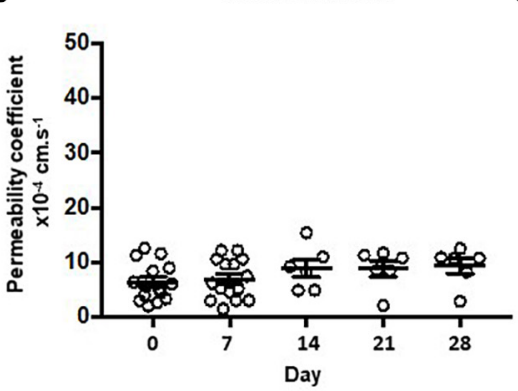

C

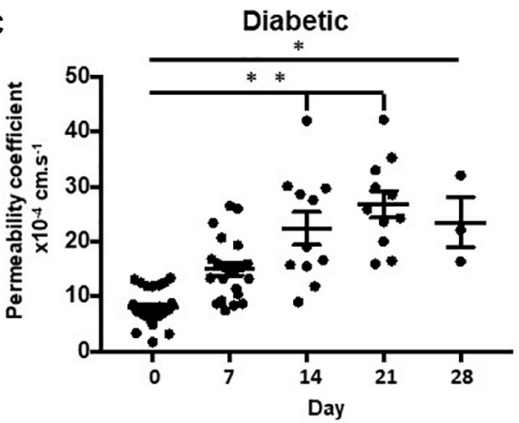

FIGURE 4 | Chemically induced diabetes significantly increased retinal vascular permeability in Norway Brown rats compared to non-diabetic controls. (A) Fundus fluorescein angiography measurements from a single rat carried out on day 0 (before STZ) and day 7 (1 week of STZ treatment). (B) Permeability was measured from control (blood glucose $7.99 \pm 0.21 \mathrm{mmo} / \mathrm{L}$ ), and (C) diabetic (blood glucose $29.75 \pm 1.63 \mathrm{mmol} / \mathrm{L}$ ) Norway Brown rats on days 0, 7, 14, 21, and 28. Apparent permeability was calculated as described in the methodology text and depicted in Figure 1. Data including mean $\pm S E M .{ }^{*} p \leq 0.001$ vs. day 0 , ${ }^{* *} p \leq 0.0001$ vs. diabetic day 0. One-way ANOVA.

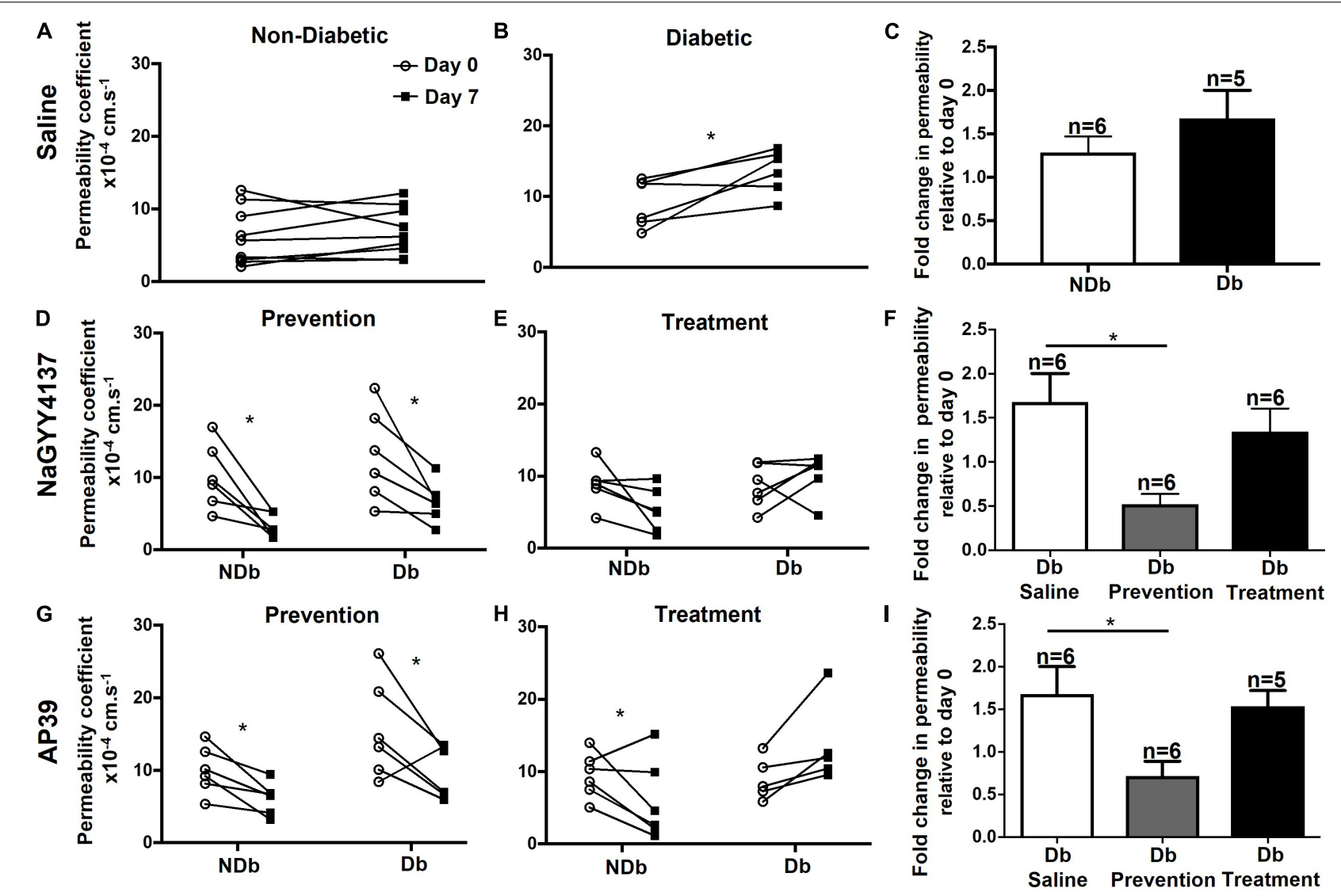

FIGURE 5 | Ocular administration of the slow-release $\mathrm{H}_{2} \mathrm{~S}$ donors reduced retinal permeability in chemically induced diabetic rats. Type I diabetes was successfully induced in rats following a single dose of STZ and animals were maintained for 1 week without insulin supplementation. Retinal vascular leak was measured on day 0 and day 7 in non- and diabetic animals following treatment. No observed increases in retinal permeability were measured on day 7 in non-diabetic animals treated with saline (A,C). In diabetic animals treated with saline a significant ( $\left.{ }^{*} P \leq 0.05\right)$ increase in retinal permeability was measured on day 7 vs. day 0 (B, C). NaGYY4137 and AP39 significantly ( ${ }^{\star} p<0.05$, paired $t$-test) reduced retinal permeability in non- and diabetic rats (D,G,F) on day 7 when given as a single intraocular preventative dose, on day 0. In addition, NaGYY4137 and AP39 reduced retinal permeability in non-diabetic rats (E,F,H,I) when administered therapeutically (day 6). In diabetic rats, NaGYY4137 and AP39 stabilized retinal permeability on day 7 in rats with pre-existing diabetes (E,F,H,I).

levels of inflammatory mediators and the diabetic retina displays characteristic features of inflammation including increased vascular permeability and leukocyte adhesion (Adamis and
Berman, 2008). Since a healthy glycocalyx is critical to maintenance of both the anti-inflammatory and permeability characteristics of a healthy endothelium, our data highlight 
A

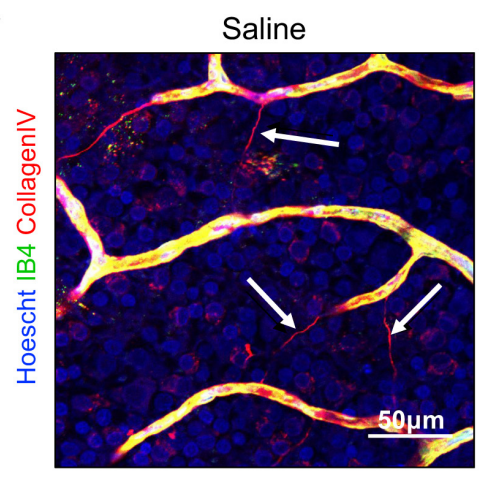

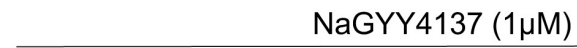
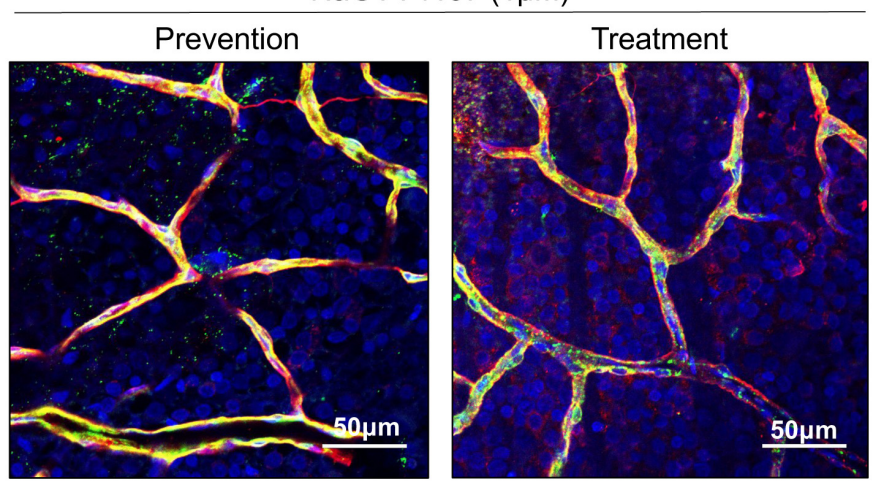

B

Acellular capillaries (collagenIV+/IB4-)

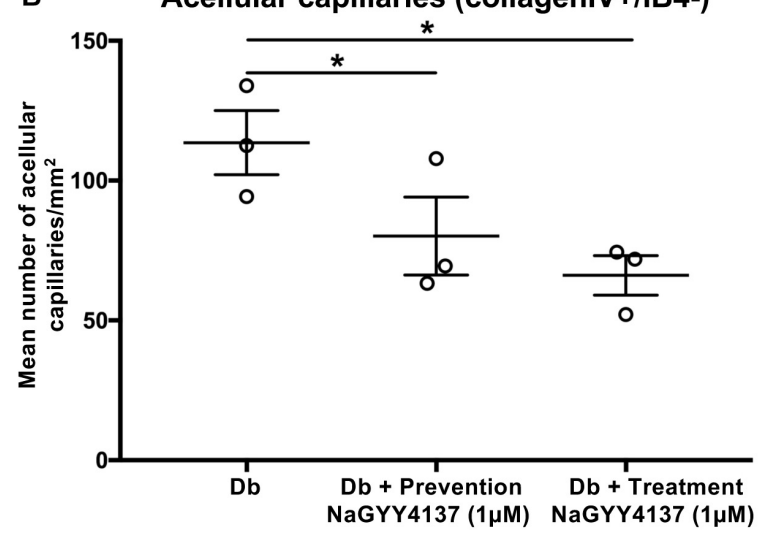

FIGURE 6 | NaGYY4137 protected against diabetes-induced increase in acellular capillaries. Norway Brown rats were given a single dose of streptozotocin $\left(50 \mathrm{mg} / \mathrm{kg}\right.$ ) to induce Type I diabetes. Rats were treated with an intraocular injection of either saline or $1 \mu \mathrm{mol} / \mathrm{L} \mathrm{H}_{2} \mathrm{~S}$ donor NaGYY4137 at day 0 (prevention) or day 6 (treatment). (A) Rats were enucleated at day 7 and whole retinae were mounted and stained with Hoescht, IB4, and collagen IV. The tissue was imaged using $20 \times$ lens. The number of capillaries positively stained for collagen IV but lacking IB4 (white arrows) were counted in three areas of the retina. (B) Acellular capillaries are expressed per $\mathrm{mm}^{2}$. Error bars represent standard errors of the mean. Statistical analysis was performed using a one-way analysis of variance corrected for false discovery rate. ${ }^{*} p \leq 0.05$.

the potential of $\mathrm{H}_{2} \mathrm{~S}$ donors as new therapeutic tools for the treatment of DR. Further investigations into optimal dosing and comparing other $\mathrm{H}_{2} \mathrm{~S}$ delivery molecules are needed to further explore this potential.

The available literature describing other research in this area is scarce. However, glycocalyx loss and enhanced leukocyte adhesion have been reported in a rat model of diabetes (Kumase et al., 2010). Additionally, a clear link between in vivo retinal glycocalyx integrity and vascular permeability has been reported by Leskova et al. (2019), who demonstrated, in mice, that enzymatic degradation of the glycocalyx is associated with enhanced retinal permeability. These data support the hypothesis that maintaining glycocalyx integrity could be a viable therapeutic strategy for DR. EC glycocalyx thickness depends on the rate of shedding and circulatory levels of glycosaminoglycans (GAG)-degrading enzyme levels (Ikegami-Kawai et al., 2003; Maxhimer et al., 2005). The previously reported association of glycocalyx reduction with increased vascular permeability and leucocyte and platelet adhesion and subsequent reversal by glycocalyx restoration in experimental animals through increased GAG synthesis (Henry and Duling, 1999; Constantinescu et al., 2003) corroborate our findings. Furthermore, Ciszewicz et al. (2009), have shown that sulodexide attenuates hyperglycemia-associated EC permeability and inflammation. Similarly, Broekhuizen et al. (2010), demonstrated that sulodexide increased vascular EC glycocalyx and reversed the increased vascular permeability in type 2 diabetes. Additionally, Niu et al. (2019), using the STZ-induced diabetic rat model used here, showed that endomucin overexpression restored the diabetes-associated loss of retinal endothelial glycocalyx and that this restoration was associated with decreased leukocyte-endothelial adhesion and a reduction in vessel leakage in rats with $\mathrm{DR}$.

The effects of $\mathrm{H}_{2} \mathrm{~S}$ on the glycocalyx are still unknown. Although early studies showed potential antioxidant effects of $\mathrm{H}_{2} \mathrm{~S}$, more recent work has shown that the reaction rate between $\mathrm{H}_{2} \mathrm{~S}$ and oxidant species, e.g., peroxide and peroxynitrite, may be too slow for oxidant scavenging activity alone to be primarily responsible for glycocalyx- and vaso-protection, especially given the low in vivo concentrations of $\mathrm{H}_{2} \mathrm{~S}$, which we have modeled using NaGYY4317 (Carballal et al., 2011). This strongly suggests that $\mathrm{H}_{2} \mathrm{~S}$ is acting via other mechanisms to maintain the glycocalyx during hyperglycemic damage, e.g., enhancing synthesis of glycocalyx components or preventing 
hyperglycemia-induced glycocalyx degradation. For instance, the glycocalyx component syndecan-1 is cleaved by matrix metalloproteinase-9 (MMP-9) and both activity and expression of the protease are known to be reduced by $\mathrm{H}_{2} \mathrm{~S}$ administration (Du et al., 2017). It has also been reported that MMP-7 can cleave chondroitin sulfate (Lipowsky, 2011) and syndecans 1 and 4 (Manon-Jensen et al., 2013) and our unpublished data indicate that NaGYY4137 inhibits MMP-7 in in vitro assays at concentrations similar to those used in the studies described here. Interestingly, our additional preliminary data indicating that NaGYY4137 reduces shedding of hyaluronic acid from cultured ECs suggest another potential action of $\mathrm{H}_{2} \mathrm{~S}$ since the significant reduction in EC glycocalyx observed in acute hyperglycemia (Nieuwdorp et al., 2006b) and in types 1 and type 2 diabetes (Nieuwdorp et al., 2006a; Broekhuizen et al., 2010) is thought to be related to increased hyaluronidase catabolism (Nieuwdorp et al., 2006a).

It is interesting to note that NaGYY4137 treatment in NG enhanced glycocalyx staining above the levels observed in NG alone (Figure 2), suggesting that $\mathrm{H}_{2} \mathrm{~S}$ supplementation alone increased glycocalyx density. As mentioned previously, the glycocalyx is a dynamic structure and thus this observation could potentially be explained by the ability of $\mathrm{H}_{2} \mathrm{~S}$ to modify glycocalyx-degrading enzymes to reduce their activity. Interestingly, $\mathrm{H}_{2} \mathrm{~S}$ is the only molecule known to induce protein $S$-persulfidation ( $S$-sulfhydration), a recently identified and unique post-translational protein modification. It is possible that the activity of glycocalyx-degrading enzymes such as heparinase might be altered by persulfidation of the cysteine residues of its active site. Additionally, cysteine residues in proteins have the potential to be redox modified by $\mathrm{H}_{2} \mathrm{~S}$ in a non-S-persulfidation manner and several potential glycocalyx-degrading enzymes, including the proteinases MMP-1 (Lohakul et al., 2021), MMP-2, MMP-7, and MMP-9, have a cysteine in their active site. Thus, as has been shown with other zinc proteases including angiotensinconverting enzyme (Laggner et al., 2007) and TNF- $\alpha$-converting enzyme ( $\mathrm{Li}$ et al., 2013), $\mathrm{H}_{2} \mathrm{~S}$ has the potential to modulate the glycocalyx-degrading enzyme activity of the proteinases, although further work is needed to confirm this hypothesis.

The effectiveness of our mitochondrial targeted $\mathrm{H}_{2} \mathrm{~S}$ donor in decreasing retinal leakage in vivo raises the possibility of mitochondrial involvement in the observed effects. Modis et al. reported that endogenous mitochondrial $\mathrm{H}_{2} \mathrm{~S}$ production was governed by MST (Módis et al., 2013). Additionally, Si et al. (2013) reported that DR was associated with significant decreases in retinal $\mathrm{H}_{2} \mathrm{~S}$ levels and expression of the $\mathrm{H}_{2} \mathrm{~S}$ synthesizing enzymes CSE, CBS, and 3MST (i.e., DR resulted in retinal $\mathrm{H}_{2} \mathrm{~S}$ deficiency) and also with increased mitochondrial permeability and respiration (Si et al., 2013), strongly suggesting extensive mitochondrial dysfunction and $\mathrm{H}_{2} \mathrm{~S}$ deficiency in the retina in DR. Vascular mitochondrial impairment induced by diabetes has previously been shown to be inhibited/reversed by sulfide administration albeit at high doses/concentrations (e.g., $300 \mu \mathrm{mol} / \mathrm{L}$ ) (Módis et al., 2013; Coletta et al., 2015), suggesting that pharmacological sulfide could overcome impaired retinal bioenergetics in DR. Although $\mathrm{NaSH}$ administration has previously been shown to reduce retinal vascular abnormalities associated with DR and "correct" mitochondrial dysfunction (Si et al., 2013), this earlier study is intriguing for several reasons. Firstly, the $\mathrm{NaSH}$ was given as a daily intraperitoneal injection (over 14 weeks) at a dose equivalent to $280 \mathrm{mmol} / \mathrm{kg}$. This was an exceptionally high and surprisingly non-lethal dose (although toxicity was not examined) given that $14 \mu \mathrm{mol} / \mathrm{kg}$ i.p. induces systemic inflammation and vascular collapse (Li et al., 2005) and the $\mathrm{LD}_{50}$ for $\mathrm{NaSH}$ is $52.6 \mu \mathrm{mol} / \mathrm{kg}$ for the same route of administration (Strickland et al., 2003). Possible toxicological constraints aside, the half-life of bolus sulfide in blood is less than a minute as it is rapidly metabolized/removed (Wang, 2002, 2012), so the precise mechanisms by which a bolus of $\mathrm{H}_{2} \mathrm{~S}$ (from $\mathrm{NaSH}$ ), administered intraperitoneally survives intact to penetrate the blood-brain barrier and selectively increase sulfide levels in the retina via this route remain elusive. Given that plasma $\mathrm{H}_{2} \mathrm{~S}$ levels have been measured at nanomolar to low micromolar concentrations, our approach to prevent/reverse DRinduced retinal vascular leakage using slow-release $\mathrm{H}_{2} \mathrm{~S}$ donors (Wei et al., 2014; John et al., 2017; Qiu et al., 2018) or $\mathrm{H}_{2} \mathrm{~S}$ delivery molecules that selectively target mitochondria (Le Trionnaire et al., 2014; Szczesny et al., 2014; Ikeda et al., 2015; Ahmad et al., 2016; Karwi et al., 2017) would overcome these concerns.

\section{CONCLUSION}

The data presented here together with previous in vivo data (Whiteman et al., 2010a) suggest that, in health, $\mathrm{H}_{2} \mathrm{~S}$ is vasculoprotective and that microvascular dysfunction in diabetes, including $\mathrm{DR}$, is associated with reduced circulating and retinal $\mathrm{H}_{2} \mathrm{~S}$ levels. Thus, diabetes may be a condition of $\mathrm{H}_{2} \mathrm{~S}$ deficiency and $\mathrm{H}_{2} \mathrm{~S}$ supplementation using slow-release and/or mitochondrial-targeted $\mathrm{H}_{2} \mathrm{~S}$ delivery molecules may represent a novel, cost-effective alternative therapy for DR.

\section{DATA AVAILABILITY STATEMENT}

The original contributions presented in the study are included in the article/supplementary material. The raw data supporting the conclusions of this article will be made available by the authors, without undue reservation.

\section{ETHICS STATEMENT}

The animal study was reviewed and approved by University of Nottingham Biological Services Unit.

\section{AUTHOR CONTRIBUTIONS}

JW, DB, and MWh conceived and planned the experiments. CA, JW, DB, and MWh took the lead in writing the manuscript. $\mathrm{CA}, \mathrm{KW}$, and NM carried out the experiments. RT and MWo synthesized the slow-release hydrogen sulfide donors. AB and WA contributed to the interpretation of the results. All authors provided critical feedback and helped shape the research, analysis, and manuscript. 


\section{FUNDING}

We wish to thank the Medical Research Council, UK (MR/M022706/1 to MWh and MWo; MR/L01985X/1 to JW, DB, and MWh), British Heart Foundation (PG/18/31/33759 to $\mathrm{AB}$ and $\mathrm{DB}$ ), Royal Society (RGS $\backslash \mathrm{R} 1 \backslash 191221$ to $\mathrm{AB}$ ) and the Brian Ridge Scholarship (RT), and the National Eye Research

\section{REFERENCES}

Adamis, A. P., and Berman, A. J. (2008). Immunological mechanisms in the pathogenesis of diabetic retinopathy. Semin. Immunopathol. 30, 65-84. doi: 10.1007/s00281-008-0111-x

Ahmad, A., Olah, G., Szczesny, B., Wood, M. E., Whiteman, M., and Szabo, C. (2016). AP39, a mitochondrially targeted hydrogen sulfide donor, exerts protective effects in renal epithelial cells subjected to oxidative stress in vitro and in acute renal injury in vivo. Shock 45, 88-97. doi: 10.1097/shk. 0000000000000478

Alexander, B. E., Coles, S. J., Fox, B. C., Khan, T. F., Maliszewski, J., Perry, A., et al. (2015). Investigating the generation of hydrogen sulfide from the phosphonamidodithioate slow-release donor GYY4137. Med. Chem. Commun. 6, 1649-1655. doi: 10.1039/c5md00170f

Allen, C. L., and Bayraktutan, U. (2009). Antioxidants attenuate hyperglycaemia-mediated brain endothelial cell dysfunction and bloodbrain barrier hyperpermeability. Diabetes Obes. Metab. 11, 480-490. doi: 10.1111/j.1463-1326.2008.00987.x

Allen, C. L., Malhi, N. K., Whatmore, J. L., Bates, D. O., and Arkill, K. P. (2020). Non-invasive measurement of retinal permeability in a diabetic rat model. Microcirculation. 27:e12623.

Ballantyne, B., Gazzard, M. F., and Swanston, D. W. (1976). The opthalmic toxicology of dichloromethane. Toxicology 6, 173-187. doi: 10.1016/0300$483 x(76) 90019-6$

Betteridge, K. B., Arkill, K. P., Neal, C. R., Harper, S. J., Foster, R. R., Satchell, S. C., et al. (2017). Sialic acids regulate microvessel permeability, revealed by novel in vivo studies of endothelial glycocalyx structure and function. J. Physiol. 595, 5015-5035. doi: 10.1113/JP274167

Brancaleone, V., Roviezzo, F., Vellecco, V., De Gruttola, L., Bucci, M., and Cirino, G. (2008). Biosynthesis of $\mathrm{H}_{2} \mathrm{~S}$ is impaired in non-obese diabetic (n.d.) mice. $B r$. J. Pharmacol. 155, 673-680. doi: 10.1038/bjp.2008.296

Brandt, K. R., and Okamoto, M. Y. (1988). Final report on the safety assessment of methylene chloride. J. Am. Coll. Toxicol. 7, 741-835. doi: 10.3109/ 10915818809078710

Broekhuizen, L. N., Lemkes, B. A., Mooij, H. L., Meuwese, M. C., Verberne, H., Holleman, F., et al. (2010). Effect of sulodexide on endothelial glycocalyx and vascular permeability in patients with type 2 diabetes mellitus. Diabetologia 53 , 2646-2655. doi: 10.1007/s00125-010-1910-x

Brownlee, M. (2001). Biochemistry and molecular cell biology of diabetic complications. Nature 414, 813-820. doi: 10.1038/414813a

Brownlee, M. (2005). The pathobiology of diabetic complications: a unifying mechanism. Diabetes 54, 1615-1625. doi: 10.2337/diabetes.54.6.1615

Carballal, S., Trujillo, M., Cuevasanta, E., Bartesaghi, S., Möller, M. N., Folkes, L. K., et al. (2011). Reactivity of hydrogen sulfide with peroxynitrite and other oxidants of biological interest. Free Radic. Biol. Med. 50, 196-205. doi: 10.1016/ j.freeradbiomed.2010.10.705

Chibber, R., Ben-Mahmud, B. M., Coppini, D., Christ, E., and Kohner, E. M. (2000). Activity of the glycosylating enzyme, core 2 GlcNAc (beta1,6) transferase, is higher in polymorphonuclear leukocytes from diabetic patients compared with age-matched control subjects: relevance to capillary occlusion in diabetic retinopathy. Diabetes 49, 1724-1730. doi: 10.2337/diabetes.49.10.1724

Ciszewicz, M., Polubinska, A., Antoniewicz, A., Suminska-Jasinska, K., and Breborowicz, A. (2009). Sulodexide suppresses inflammation in human endothelial cells and prevents glucose cytotoxicity. Transl. Res. 153, 118-123. doi: $10.1016 /$ j.trsl.2008.12.007

Coletta, C., Módis, K., Szczesny, B., Brunyánszki, A., Oláh, G., Rios, E. C., et al. (2015). Regulation of vascular tone, angiogenesis and cellular bioenergetics by
Centre and Masonic Charitable Foundation for funding this study.

\section{ACKNOWLEDGMENTS}

We wish to thank Bridget Fox for her assistance with the preliminary studies.

the 3-mercaptopyruvate sulfurtransferase/H2S pathway: functional impairment by hyperglycemia and restoration by DL- $\alpha$-lipoic acid. Mol. Med. 21, 1-14. doi: 10.2119/molmed.2015.00035

Constantinescu, A. A., Vink, H., and Spaan, J. A. (2003). Endothelial cell glycocalyx modulates immobilization of leukocytes at the endothelial surface. Arterioscler. Thromb. Vasc. Biol. 23, 1541-1547. doi: 10.1161/01.atv.0000085630.24353.3d

Du, J., Jin, H., and Yang, L. (2017). Role of hydrogen sulfide in retinal diseases. Front. Pharmacol. 8:588. doi: 10.3389/fphar.2017.00588

Gerő, D., Torregrossa, R., Perry, A., Waters, A., Le-Trionnaire, S., Whatmore, J. L., et al. (2016). The novel mitochondria-targeted hydrogen sulfide $\left(\mathrm{H}_{2} \mathrm{~S}\right)$ donors AP123 and AP39 protect against hyperglycemic injury in microvascular endothelial cells in vitro. Pharmacol. Res. 113, 186-198. doi: 10.1016/j.phrs. 2016.08.019

Gillies, M. C., Su, T., Stayt, J., Simpson, J. M., Naidoo, D., and Salonikas, C. (1997). Effect of high glucose on permeability of retinal capillary endothelium in vitro. Invest. Ophthalmol. Vis. Sci. 38, 635-642.

Henry, C. B., and Duling, B. R. (1999). Permeation of the luminal capillary glycocalyx is determined by hyaluronan. Am. J. Physiol. 277, H508-H514.

Ikeda, K., Marutani, E., Hirai, S., Wood, M. E., Whiteman, M., and Ichinose, F. (2015). Mitochondria-targeted hydrogen sulfide donor AP39 improves neurological outcomes after cardiac arrest in mice. Nitric Oxide 49, 90-96. doi: 10.1016/j.niox.2015.05.001

Ikegami-Kawai, M., Suzuki, A., Karita, I., and Takahashi, T. (2003). Increased hyaluronidase activity in the kidney of streptozotocin-induced diabetic rats. J. Biochem. 134, 875-880. doi: 10.1093/jb/mvg214

Jeansson, M., and Haraldsson, B. (2003). Glomerular size and charge selectivity in the mouse after exposure to glucosaminoglycan-degrading enzymes. J. Am. Soc. Nephrol. 14, 1756-1765. doi: 10.1097/01.asn.0000072742.02714.6e

John, A., Kundu, S., Pushpakumar, S., Fordham, M., Weber, G., Mukhopadhyay, M., et al. (2017). GYY4137, a hydrogen sulfide donor modulates miR194dependent collagen realignment in diabetic kidney. Sci. Rep. 7:10924.

Jones, D. A., Smith, C. W., and McIntire, L. V. (1995). Effects of Fluid Shear Stress on Leukocyte Adhesion to Endothelial Cells. Physiology and Pathophysiology of Leukocyte Adhesion. New York, NY: Oxford University Press, 148-168.

Kabil, O., and Banerjee, R. (2014). Enzymology of $\mathrm{H}_{2} \mathrm{~S}$ biogenesis, decay and signaling. Antioxid. Redox Signal. 20, 770-782. doi: 10.1089/ars.2013.5339

Kanagy, N. L., Szabo, C., and Papapetropoulos, A. (2017). Vascular biology of hydrogen sulfide. Am. J. Physiol. Cell Physiol. 312, C537-C549.

Karwi, Q. G., Bornbaum, J., Boengler, K., Torregrossa, R., Whiteman, M., Wood, M. E., et al. (2017). AP39, a mitochondria-targeting hydrogen sulfide $\left(\mathrm{H}_{2} \mathrm{~S}\right)$ donor, protects against myocardial reperfusion injury independently of salvage kinase signalling. Br. J. Pharmacol. 174, 287-301. doi: 10.1111/bph.13688

Kielhorn, J., and Rosner, G. (1996). Environmental Health Criteria: Morpholine. International Programme on Chemical Safety. Geneva: World Health Organization.

Kumase, F., Morizane, Y., Mohri, S., Takasu, I., Ohtsuka, A., and Ohtsuki, H. (2010). Glycocalyx degradation in retinal and choroidal capillary endothelium in rats with diabetes and hypertension. Acta Med. Okayama 64, 277-283.

Kundu, S., Pushpakumar, S. B., Tyagi, A., Coley, D., and Sen, U. (2013). Hydrogen sulfide deficiency and diabetic renal remodeling: role of matrix metalloproteinase-9. Am. J. Physiol. Endocrinol. Metab. 304, E1365-E1378.

Laggner, H., Hermann, M., Esterbauer, H., Muellner, M. K., Exner, M., Gmeiner, B. M., et al. (2007). The novel gaseous vasorelaxant hydrogen sulfide inhibits angiotensin-converting enzyme activity of endothelial cells. J. Hypertens. 25, 2100-2104. doi: 10.1097/hjh.0b013e32829b8fd0 
Landsverk, S. A., Tsai, A. G., Cabrales, P., and Intaglietta, M. (2012). Impact of enzymatic degradation of the endothelial glycocalyx on vascular permeability in an awake hamster model. Crit. Care Res. Pract. 2012:842545.

Le Trionnaire, S., Perry, A., Szczesny, B., Szabo, C., Winyard, P. G., Whatmore, J. L., et al. (2014). The synthesis and functional evaluation of a mitochondriatargeted hydrogen sulfide donor, (10-oxo-10-(4-(3-thioxo-3H-1,2-dithiol-5yl)phenoxy)decyl)triphenylphosphonium bromide (AP39). Med. Chem. Comm. 5, 728-736. doi: 10.1039/c3md00323j

Lee, Z. W., Zhou, J., Chen, C. S., Zhao, Y., Tan, C. H., Li, L., et al. (2011). The slow-releasing hydrogen sulfide donor, GYY4137, exhibits novel anti-cancer effects in vitro and in vivo. PloS One. 6:e21077. doi: 10.1371/journal.pone.002 1077

Leskova, W., Pickett, H., Eshaq, R. S., Shrestha, B., Pattillo, C. B., and Harris, N. R. (2019). Effect of diabetes and hyaluronidase on the retinal endothelial glycocalyx in mice. Exp. Eye Res. 179, 125-131. doi: 10.1016/j.exer.2018.11. 012

Li, L., Bhatia, M., Zhu, Y. Z., Zhu, Y. C., Ramnath, R. D., Wang, Z. J., et al. (2005). Hydrogen sulfide is a novel mediator of lipopolysaccharide-induced inflammation in the mouse. FASEB J. 19, 1196-1198. doi: 10.1096/fj.04-3583fje

Li, L., Fox, B., Keeble, J., Salto-Tellez, M., Winyard, P. G., Wood, M. E., et al. (2013). The complex effects of the slow-releasing hydrogen sulfide donor GYY4137 in a model of acute joint inflammation and in human cartilage cells. J. Cell Mol. Med. 17, 365-376. doi: 10.1111/jcmm.12016

Li, L., Whiteman, M., Guan, Y. Y., Neo, K. L., Cheng, Y., Lee, S. W., et al. (2008). Characterization of a novel, water-soluble hydrogen sulfide-releasing molecule (GYY4137): new insights into the biology of hydrogen sulfide. Circulation 117, 2351-2360. doi: 10.1161/circulationaha.107.753467

Lipowsky, H. H. (2011). Protease activity and the role of the endothelial glycocalyx in inflammation. Drug Discov. Today Dis. Models 8, 57-62. doi: 10.1016/j. ddmod.2011.05.004

Lohakul, J., Jeayeng, S., Chaiprasongsuk, A., Torregrossa, R., Wood, M., Saelim, M., et al. (2021). Mitochondria-targeted hydrogen sulfide delivery molecules protect against UVA-induced photoimaging in dermal fibroblasts, and in mouse skin in vivo. Antioxid. Redox Signal. [Epub ahead of print].

Manon-Jensen, T., Multhaupt, H. A., and Couchman, J. R. (2013). Mapping of matrix metalloproteinase cleavage sites on syndecan- 1 and syndecan- 4 ectodomains. FEBS J. 280, 2320-2331. doi: 10.1111/febs.12174

Maxhimer, J. B., Somenek, M., Rao, G., Pesce, C. E., Baldwin, D. Jr., Gattuso, P., et al. (2005). Heparanase-1 gene expression and regulation by high glucose in renal epithelial cells: a potential role in the pathogenesis of proteinuria in diabetic patients. Diabetes 54, 2172-2178. doi: 10.2337/diabetes.54.7.2172

Mitidieri, E., Gurgone, D., Caiazzo, E., Tramontano, T., Cicala, C., Sorrentino, R., et al. (2020). L-cysteine/cystathionine- $\beta$-synthase-induced relaxation in mouse aorta involves a L-serine/sphingosine-1-phosphate/NO pathway. $\mathrm{Br}$. J. Pharmacol. 177, 734-744. doi: 10.1111/bph.14654

Módis, K., Asimakopoulou, A., Coletta, C., Papapetropoulos, A., and Szabo, C. (2013). Oxidative stress suppresses the cellular bioenergetic effect of the 3-mercaptopyruvate sulfurtransferase/hydrogen sulfide pathway. Biochem. Biophys. Res. Commun. 433, 401-407. doi: 10.1016/j.bbrc.2013.02.131

Módis, K., Bos, E. M., Calzia, E., van Goor, H., Coletta, C., Papapetropoulos, A., et al. (2014). Regulation of mitochondrial bioenergetic function by hydrogen sulfide. Part II. Pathophysiological and therapeutic aspects. Br. J. Pharmacol. 171, 2123-2146. doi: 10.1111/bph.12368

Montoya, L. A., and Pluth, M. D. (2016). Organelle-targeted $\mathrm{H}_{2} \mathrm{~S}$ probes enable visualization of the subcellular distribution of $\mathrm{H}_{2} \mathrm{~S}$ donors. Anal. Chem. 88, 5769-5774. doi: 10.1021/acs.analchem.6b00087

Ng, L. T., Gruber, J., and Moore, P. K. (2018). Is there a role of $\mathrm{H}_{2} \mathrm{~S}$ in mediating health span benefits of caloric restriction? Biochem. Pharmacol. 149, 91-100. doi: 10.1016/j.bcp.2018.01.030

Nieuwdorp, M., Mooij, H. L., Kroon, J., Atasever, B., Spaan, J. A., Ince, C., et al. (2006a). Endothelial glycocalyx damage coincides with microalbuminuria in type 1 diabetes. Diabetes 55, 1127-1132. doi: 10.2337/diabetes.55.04.06.db051619

Nieuwdorp, M., van Haeften, T. W., Gouverneur, M. C., Mooij, H. L., van Lieshout, M. H., Levi, M., et al. (2006b). Loss of endothelial glycocalyx during acute hyperglycemia coincides with endothelial dysfunction and coagulation activation in vivo. Diabetes 55, 480-486. doi: 10.2337/diabetes.55.02.06.db051103
Niu, T., Zhao, M., Jiang, Y., Xing, X., Shi, X., Cheng, L., et al. (2019). Endomucin restores depleted endothelial glycocalyx in the retinas of streptozotocin-induced diabetic rats. FASEB J. 33, 13346-13357. doi: 10.1096/fj.201901161r

Onions, K. L., Gamez, M., Buckner, N. R., Baker, S. L., Betteridge, K. B., Desideri, S., et al. (2019). VEGFC reduces glomerular albumin permeability and protects against alterations in VEGF receptor expression in diabetic nephropathy. Diabetes 68, 172-187. doi: 10.2337/db18-0045

Peake, B. F., Nicholson, C. K., Lambert, J. P., Hood, R. L., Amin, H., Amin, S., et al. (2013). Hydrogen sulfide preconditions the $\mathrm{db} / \mathrm{db}$ diabetic mouse heart against ischemia-reperfusion injury by activating Nrf2 signaling in an Erk-dependent manner. Am. J. Physiol. Heart Circ. Physiol. 304, H1215-H1224.

Qiu, Y., Wu, Y., Meng, M., Luo, M., Zhao, H., Sun, H., et al. (2018). GYY4137 protects against myocardial ischemia/reperfusion injury via activation of the PHLPP-1/Akt/Nrf2 signaling pathway in diabetic mice. J. Surg. Res. 225, 29-39. doi: 10.1016/j.jss.2017.12.030

Ratney, R. S., Wegman, D. H., and Elkins, H. B. (1974). In vivo conversion of methylene chloride to carbon monoxide. Arch. Environ. Health 28, 223-226. doi: 10.1080/00039896.1974.10666472

Saker, S., Stewart, E. A., Browning, A. C., Allen, C. L., and Amoaku, W. M. (2014). The effect of hyperglycaemia on permeability and the expression of junctional complex molecules in human retinal and choroidal endothelial cells. Exp. Eye Res. 121, 161-167. doi: 10.1016/j.exer.2014.02.016

Sander, B., Thornit, D. N., Colmorn, L., Strøm, C., Girach, A., Hubbard, L. D., et al. (2007). Progression of diabetic macular edema: correlation with blood retinal barrier permeability, retinal thickness, and retinal vessel diameter. Invest. Ophthalmol. Vis. Sci. 48, 3983-3987. doi: 10.1167/iovs.06-1102

Si, Y. F., Wang, J., Guan, J., Zhou, L., Sheng, Y., and Zhao, J. (2013). Treatment with hydrogen sulfide alleviates streptozotocin-induced diabetic retinopathy in rats. Br. J. Pharmacol. 169, 619-631. doi: 10.1111/bph.12163

Singh, A., Satchell, S. C., Neal, C. R., McKenzie, E. A., Tooke, J. E., and Mathieson, P. W. (2007). Glomerular endothelial glycocalyx constitutes a barrier to protein permeability. J. Am. Soc. Nephrol. 18, 2885-2893. doi: 10.1681/asn.200701 0119

Sohn, O. S., Fiala, E. S., Conaway, C. C., and Weisburger, J. H. (1982). Metabolism and disposition of morphine in the rat, hamster, and guinea pig. Toxicol. Appl. Pharmacol. 64, 486-491. doi: 10.1016/0041-008x(82)90246-0

Strickland, J., Cummings, A., Spinnato, J. A., and Liccione, J. J. (2003). Toxicological Review of Hydrogen Sulfide (CAS No. 7783-06-4). In Support of Summary Information on the Integrated Risk Information System (IRIS). Washington, DC: U.S. Environmental Protection Agency.

Sun, Y., Tian, Z., Liu, N., Zhang, L., Gao, Z., Sun, X., et al. (2018). Exogenous $\mathrm{H}_{2} \mathrm{~S}$ switches cardiac energy substrate metabolism by regulating SIRT3 expression in db/db mice. J. Mol. Med. (Berl). 96, 281-299. doi: 10.1007/s00109-017-1616-3

Sundd, P., Pospieszalska, M. K., Cheung, L. S., Konstantopoulos, K., and Ley, K. (2011). Biomechanics of leukocyte rolling. Biorheology 48, 1-35. doi: 10.3233/ bir-2011-0579

Suzuki, K., Olah, G., Modis, K., Coletta, C., Kulp, G., Gerö, D., et al. (2011). Hydrogen sulfide replacement therapy protects the vascular endothelium in hyperglycemia by preserving mitochondrial function. Proc. Natl. Acad. Sci. U.S.A. 108, 13829-13834. doi: 10.1073/pnas. 1105121108

Suzuki, K., Sagara, M., Aoki, C., Tanaka, S., and Aso, Y. (2017). Clinical implication of plasma hydrogen sulfide levels in Japanese patients with Type 2 diabetes. Intern. Med. 56, 17-21. doi: 10.2169/internalmedicine.56.7403

Szabo, C. (2012). Roles of hydrogen sulfide in the pathogenesis of diabetes mellitus and its complications. Antioxid. Redox Signal. 17, 68-80. doi: 10.1089/ars.2011. 4451

Szabo, C. (2017). Hydrogen sulfide, an enhancer of vascular nitric oxide signaling: mechanisms and implications. Am. J. Physiol. Cell Physiol. 312, C3-C15.

Szabo, C., Ransy, C., Módis, K., Andriamihaja, M., Murghes, B., Coletta, C., et al. (2014). Regulation of mitochondrial bioenergetic function by hydrogen sulfide. Part I. Biochemical and physiological mechanisms. Br. J. Pharmacol. 171, 2099-2122. doi: 10.1111/bph.12369

Szczesny, B., Módis, K., Yanagi, K., Coletta, C., Le Trionnaire, S., Perry, A., et al. (2014). AP39, a novel mitochondria-targeted hydrogen sulfide donor, stimulates cellular bioenergetics, exerts cytoprotective effects and protects against the loss of mitochondrial DNA integrity in oxidatively stressed endothelial cells in vitro. Nitric Oxide 41, 120-130. 
Takano, T., and Miyazaki, Y. (1988). Metabolism of dichloromethane and the subsequent binding of its product, carbon monoxide, to cytochrome P-450 in perfused rat liver. Toxicol. Lett. 40, 93-96. doi: 10.1016/0378-4274(88)90187-7

Tao, B. B., Liu, S. Y., Zhang, C. C., Fu, W., Cai, W. J., Wang, Y., et al. (2013). VEGFR2 functions as an $\mathrm{H}_{2} \mathrm{~S}$-targeting receptor protein kinase with its novel Cys1045-Cys1024 disulfide bond serving as a specific molecular switch for hydrogen sulfide actions in vascular endothelial cells. Antioxid. Redox Signal. 19, 448-464. doi: 10.1089/ars.2012.4565

Toxicology-cosmetic ingredient review (1989). 6 Final report on the safety assessment of morpholine. J. Am. Coll. Toxicol. 8:707. doi: 10.3109/ 10915818909010528

Wang, R. (2002). Two's company, three's a crowd: can $\mathrm{H}_{2} \mathrm{~S}$ be the third endogenous gaseous transmitter? FASEB J. 16, 1792-1798. doi: 10.1096/fj.02-0211hyp

Wang, R. (2012). Physiological implications of hydrogen sulfide: a whiff exploration that blossomed. Physiol. Rev. 92, 791-896. doi: 10.1152/physrev. 00017.2011

Wei, W. B., Hu, X., Zhuang, X. D., Liao, L. Z., and Li, W. D. (2014). GYY4137, a novel hydrogen sulfide-releasing molecule, likely protects against high glucoseinduced cytotoxicity by activation of the AMPK/mTOR signal pathway in H9c2 cells. Mol. Cell Biochem. 389, 249-256. doi: 10.1007/s11010-013-1946-6

Whiteman, M., Gooding, K. M., Whatmore, J. L., Ball, C. I., Mawson, D., Skinner, K., et al. (2010a). Adiposity is a major determinant of plasma levels of the novel vasodilator hydrogen sulphide. Diabetologia 53, 1722-1726. doi: 10.1007/ s00125-010-1761-5

Whiteman, M., Le Trionnaire, S., Chopra, M., Fox, B., and Whatmore, J. (2011). Emerging role of hydrogen sulfide in health and disease: critical appraisal of biomarkers and pharmacological tools. Clin. Sci. (Lond). 121, 459-488. doi: $10.1042 / \operatorname{cs} 20110267$

Whiteman, M., Li, L., Rose, P., Tan, C. H., Parkinson, D. B., and Moore, P. K. (2010b). The effect of hydrogen sulfide donors on lipopolysaccharide-induced formation of inflammatory mediators in macrophages. Antioxid. Redox Signal. 12, 1147-1154. doi: 10.1089/ars.2009.2899

Whiteman, M., and Winyard, P. G. (2011). Hydrogen sulfide and inflammation: the good, the bad, the ugly and the promising. Expert. Rev. Clin. Pharmacol. 4, 13-32. doi: 10.1586/ecp.10.134

Yang, G., Wu, L., Jiang, B., Yang, W., Qi, J., Cao, K., et al. (2008). $\mathrm{H}_{2} \mathrm{~S}$ as a physiologic vasorelaxant: hypertension in mice with deletion of cystathionine gamma-lyase. Science 322, 587-590. doi: 10.1126/science.1162667
Yusuf, M., Kwong Huat, B. T., Hsu, A., Whiteman, M., Bhatia, M., and Moore, P. K. (2005). Streptozotocin-induced diabetes in the rat is associated with enhanced tissue hydrogen sulfide biosynthesis. Biochem. Biophys. Res. Commun. 333, 1146-1152. doi: 10.1016/j.bbrc.2005.06.021

Zhao, H., Lu, S., Chai, J., Zhang, Y., Ma, X., Chen, J., et al. (2017). Hydrogen sulfide improves diabetic wound healing in ob/ob mice via attenuating inflammation. J. Diabetes Complications 31, 1363-1369. doi: 10.1016/j.jdiacomp.2017.06. 011

Zhou, X., Feng, Y., Zhan, Z., and Chen, J. (2014). Hydrogen sulfide alleviates diabetic nephropathy in a streptozotocin-induced diabetic rat model. J. Biol. Chem. 289, 28827-28834. doi: 10.1074/jbc.m114.596593

Zivanovic, J., Kouroussis, E., Kohl, J. B., Adhikari, B., Bursac, B., Schott-Roux, S., et al. (2019). Selective persulfide detection reveals evolutionarily conserved antiaging effects of S-sulfhydration. Cell Metab. 30, 1152-1170.e13.

Conflict of Interest: MWh, RT, and MWo, and the University of Exeter have intellectual property (patent filings) related to hydrogen sulfide delivery molecules and their therapeutic use. MWh was a consultant to MitoRx Therapeutics (Oxford).

The remaining authors declare that the research was conducted in the absence of any commercial or financial relationships that could be construed as a potential conflict of interest.

Publisher's Note: All claims expressed in this article are solely those of the authors and do not necessarily represent those of their affiliated organizations, or those of the publisher, the editors and the reviewers. Any product that may be evaluated in this article, or claim that may be made by its manufacturer, is not guaranteed or endorsed by the publisher.

Copyright (C) 2021 Allen, Wolanska, Malhi, Benest, Wood, Amoaku, Torregrossa, Whiteman, Bates and Whatmore. This is an open-access article distributed under the terms of the Creative Commons Attribution License (CC BY). The use, distribution or reproduction in other forums is permitted, provided the original author(s) and the copyright owner(s) are credited and that the original publication in this journal is cited, in accordance with accepted academic practice. No use, distribution or reproduction is permitted which does not comply with these terms. 